\title{
Burial Typology: Remarks and Discussion
}

\author{
Mahmoud El-Tayeb
}

Answers to some, if not all, of the questions concerning the date and cultural horizon of the cemetery were found during the first season of excavation. Even in the face of the limited evidence, it can safely be said that the local community was class-based and well-organized. There is also much that confirms the homogeneity of Early Makurian culture in the Dongola Reach. The rectangular, vertical shaft with side niche, which is a standard feature of burials in the region between the Third and Fourth Cataracts, is represented by tumulus 22. The general rule for shafts of this type is that they are aligned east-west with the burial niche hewn into the south wall. Nonetheless, differences in shaft orientation and niche location have also been noted at other cemeteries. Tumuli 2 and 23 belong to a rare type of burial that originated from a simple rectangular shaft. So far the only parallels for these tumuli are T1 and $\mathrm{T}_{4}$ recorded at the cemetery in Hammur-Abbassiya, about $150 \mathrm{~km}$ downstream from El-Zuma. The mysterious tunnels in the Hammur and El-Zuma burials are still a subject of considerable debate. Although in three cases the burials were entered through these tunnels, either to ransack or reuse the graves, the original function of the tunnels remains obscure. Tomb plundering through tunnels was a common practice in northern Nubia, as witnessed in Gemmai and Qustul, but the tunnels in Hammur and El-Zuma are far larger and more elaborate, which leaves no room for doubt that they were not dug by robbers [Fig. 4.1]. It has been assumed in recent studies that these tunnels were constructed intentionally for some ritual purpose connected with the main burial. Further excavations at El-Zuma and Hammur may throw more light on some of these unresolved questions.

Meanwhile, a study of grave typology, burial traditions, and the highly distinctive red wheel-made pottery (cups and bowls) found in the El-Zuma burials led to the three principal types of tumuli at this site being dated to

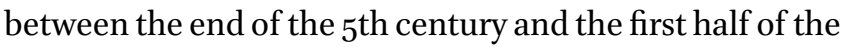
6 th century AD.

Subsequent excavations confirmed the results of the first season concerning the classification and dating of the cemetery, contributing to the known typology of type III tumuli, which are the smallest tombs at this cemetery in terms of both their super- and substructures. The standard configuration consists of a rectangular shaft cut ver- tically towards the bottom, provided with a lateral niche (seldom more than one) at the base. Most of the burial chambers discovered so far in the Dongola Reach were cut into the longer, southern side of shafts oriented east-west, although other locations for the niche have been observed at cemeteries elsewhere. To date nine burials of type III have been excavated at the El-Zuma cemetery. The excavations revealed that in all of these nine tombs, the shafts are oriented north-south with a single side niche hewn into the west wall of the shaft.

In contrast, it seems that certain innovations were introduced in the construction of the main burial chamber in tumuli of types I and II, where invariably the main burial chamber was found cut into the south wall of the shaft in all 19 burials, in a similar manner to two tombs at Hammur-Abbassiya and one at Tanqasi (Godlewski 2008, 469-476; Mahmoud El-Tayeb 2003).

Two of the four known shafts of type III burials were trapezoidal in plan, though whether by chance or design remains to be determined. Whatever the case, this feature undoubtedly renders these tumuli reminiscent of a type of burial with a shortened descending ramp rather than a rectangular shaft (as a matter of fact, tombs with descending ramps, both long and short, running east-west and dated to the Meroitic and post-Meroitic periods, are quite common in Central Sudan, but are rarely found in the Dongola Reach). Could it be that we are dealing here with two separate burial traditions, one a survival from Meroitic times - type II I with a trapezoidal shaft and burial chamber cut into the west side - and the other an evolutionary development of some kind with super/substructures and burial chambers in the south wall, as represented by the tumuli of types I and II?

Some general comments on the pottery are essential at this point (for a detailed report, see KlimaszewskaDrabot 2008, 477-491). Despite extensive looting, especially of the main chambers of tumuli 5 and 25 , the robbers left behind a substantial group of complete vessels of various types and large quantities of sherds. The repertoire is a rich one, ranging from large beer jars and cooking pots to small bowls and cups, most of them of wheel-made red ware. The beer jars include small rounded bottles, chiefly with a short narrow neck and smoothed external surface, comprising both red and black ware; 


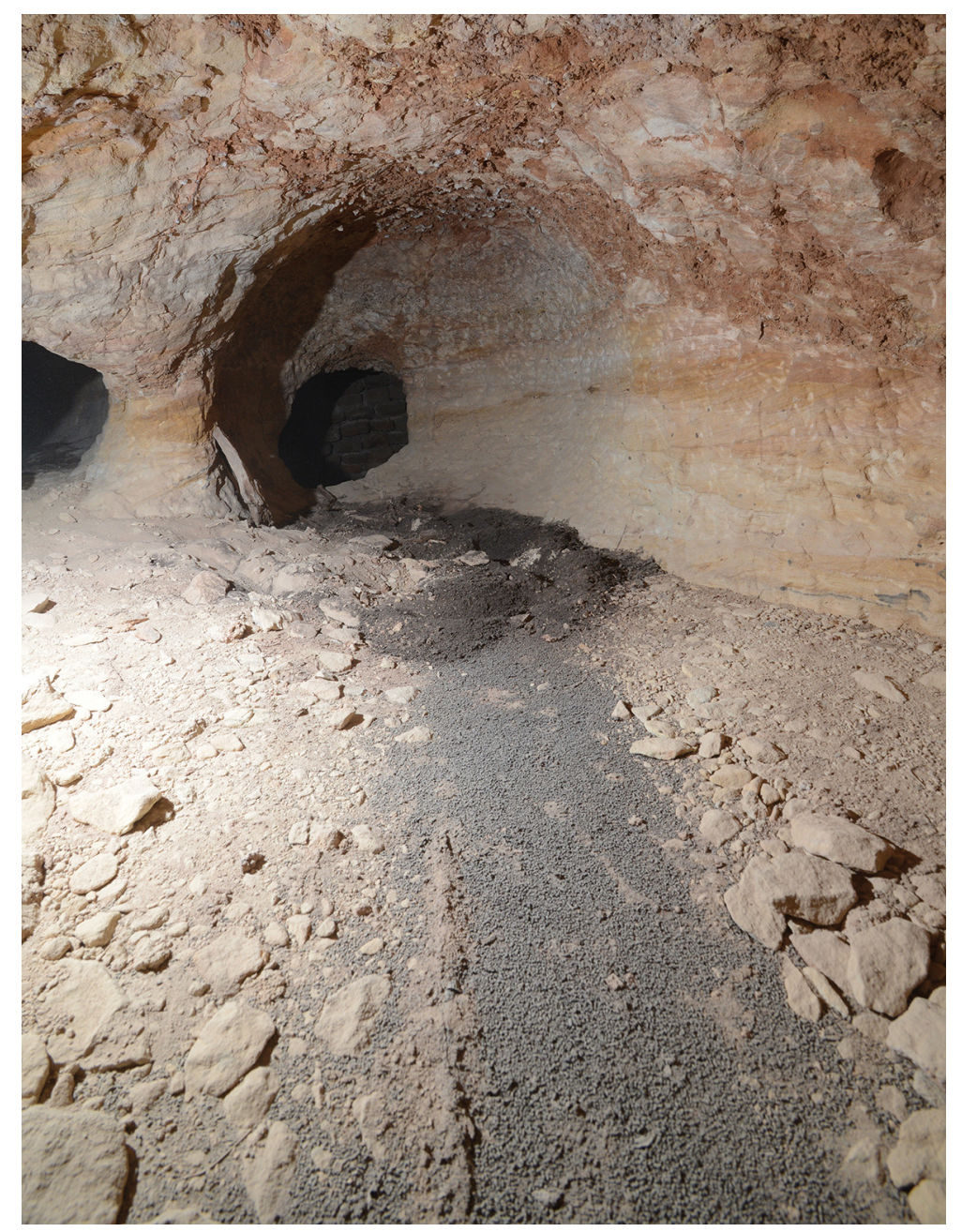

FIGURE 4.1 Eastern part of the tunnel of tumulus 7 showing evidence of 'secret' intruders - probably rats and bats PHOTO BY A. KAMROWSKI

medium-sized bottles of a very specific type, almost ovoid in shape, featuring a long, narrow neck and low shoulders decorated with two small bosses (Klimaszewska-Drabot 2010b, 483, Fig. 3: Z25/4); and finally, large globular vessels $(40-50 \mathrm{~cm}$ in diameter) with a medium-long or long neck and an external surface which is plain but smoothed. The beer jar from chamber 2 in tumulus 5 is indeed one of the largest complete handmade vessels of this kind ever found in the Dongola Reach. This well-manufactured vessel has a body diameter of $57.3 \mathrm{~cm}$, a neck height of $21.4 \mathrm{~cm}$, a mouth width of $10.8 \mathrm{~cm}$, and a full height of about $75 \mathrm{~cm}$. It bears a greater resemblance to vessels made in Central Sudan (between the Fifth and Sixth Cataracts) than to anything from the Dongola Reach (Lenoble 1992, 79-97). The bowls are, again, characteristic of the Dongola Reach between the Third and Fourth Nile Cataracts. These are wheel-made products decorated with parallel grooves or left undecorated (Mahmoud El-Tayeb 1994, 65-79; Phillips and Mahmoud El-Tayeb 2003, 458-462). Three examples with flat rims resemble bowls from El-Kadada in Central Sudan (Lenoble 1987). The fourth one appears to be of northern origin, resembling a goblet of X-Group type (Williams 1991). A red-ware footed table amphora found in chamber 2 of tumulus 25 merits special attention; it is most probably a locally produced imitation of a type imported from the north. Other examples of such vessels with ovoid body, heavy handles, red-slipped on the outside, were discovered in tumuli 2, 15 and 16 (see Volume II, pages 274-275).

The grave goods that survived in the looted tombs comprised beads, metal implements, and spear- and arrowheads. The richness of these offerings, despite instances of plundering, attest beyond all doubt to the high rank of the individuals buried at this cemetery. 
accidental distortion of the intended ground plan. Based on the two burials excavated during the second season The burial typology, which was formulated during the course of the first season's work at El-Zuma, requires closer scrutiny and verification after the completion of the excavations. Some of the tumuli that were classified as flattopped mounds, for instance T.11, T.13, and T.19, need to be re-evaluated. As a result of their excavation, some doubts have arisen as to their original form. Uncertainty concerns the higher (east) side of the mound: was it accidentally formed by the grave robbers when they started to unearth the shaft, or was it a deliberate design? Tumuli intentionally constructed in this manner have been noted at other sites upstream in the Fourth Cataract region, among them the cemetery of El-Haraz near Jebel Kulgeili (Ali Mohammed and Hussein 1999, 60-70), excavated by the National Corporation for Antiquities and Museums together with the Department of Archaeology of Dongola University at Karima, and the one at Ab-Heregil excavated by the mission of Gdańsk Archaeological Museum (Mahmoud El-Tayeb and Kołosowska 2007, 21-22, Fig. 11). The second question concerns the substructure of T.11 and its L-shaped shaft. Of all the excavated burials, T.11 is the only one with an L-shaped shaft, differing from the wellknown U-shaped shafts found in tumuli of types I and II. The nearest parallel to T.11's shaft comes from a burial in a cemetery near the village of Abkur, about $100 \mathrm{~km}$ downstream of El-Zuma. Another variant of this shaft type was found at Firka in northern Nubia (Żurawski 2003, 222, Fig. 4; Emery and Kirwan 1938). The distinctive construction of the super- and substructure, which has no parallel at the El-Zuma cemetery, can be classified as a sub-type of type II El-Zuma mounds. Confirmation of this suggestion has to await further investigation of other mounds with similar superstructures.

During the second season, excavation of one of the small tumuli (T.19, designated type III) revealed a shaft with a slightly unusual ground plan. Instead of the wellknown rectangular shape, the shaft appeared to be of trapezoidal plan with a side niche cut into the west wall (Mahmoud El-Tayeb 2010, 474-475, Fig. 8). It is commonly accepted that the simplest type of Early Makurian burial has a rectangular, vertical shaft, as recorded in type III tumulus 22 and at a number of other burial sites in the region, such as Tanqasi (Shinnie 1954), El-Ghaddar South and Northern Cemeteries (Lenoble 1987, Pl. IV c, 20) and El-Kassinger Bahry (Kołosowska and Borcowski 2014). Initially, it was thought that the trapezoidal shaft was simply a misshapen rectangular one produced by haphazard digging. However, the discovery of three more burials with trapezoidal shafts makes it less likely that this was an (2007), it was suggested in a previous article that such a shaft might have represented a shortened version of the well-known burials with an east-west dromos terminating in a burial chamber, usually hewn into the west end of the descending dromos. To date, about five shafts of this type have been found at El-Zuma. Graves with similar plans have also been discovered in the wider region, near Jebel El-Alim, during a rescue excavation conducted by a team from the National Corporation for Antiquities and Museums led by the Senior Antiquities Inspector ElTahir El-Nur (El-Tahir, personal communication, 2010). At this stage of research it is too early to come to any definite conclusions on this subject, and whether tumuli with the aforementioned features should be classified as sub-types remains an unresolved issue.

Tumulus 28 is the only one of the nine type III burials at El-Zuma that features a structural modification in the form of a secondary chamber. This was, however, a known practice in the Dongola Reach between the Third and Fourth Nile Cataracts since the first phase of the Terminal Meroitic period (post-Meroitic Phase I, AD 350-45o). The nearest parallels were discovered during the survey project carried out in the Fourth Nile Cataract region. The best examples for the modification of the simple rectangular shaft come from the cemeteries at El-Kassinger Bahry, some $20 \mathrm{~km}$ upstream of Karima. One of them is T.45/1, which has a rectangular, vertical shaft aligned east-west, with the main burial chamber cut into the southern long wall, in which the body was laid in a contracted position, on its right side, head due east, facing north. A number of offerings were found with the body, while on the short east side of the shaft a secondary chamber was furnished with more grave offerings (Paner 1998, 117, 118, Figs. 3, 4). A further example from cemetery 47 at El-Kassinger Bahry is burial T.47/1, in which the main burial is cut into the west wall of the shaft, but the secondary chamber is hewn into the short south wall (Paner 1998, 128, Fig. 20). Another unique modification was discovered in the Fourth Cataract region at $\mathrm{Ab}$-Heregil cemetery. In this case, a rectangular shaft aligned roughly north-south led down to a semicircular chamber cut into the short southern side of the shaft and extending into the middle of the long western side. In a highly unusual burial practice, the deceased was buried in the short southern side of the chamber (Mahmoud El-Tayeb and Kołosowska 2005, 68-69, Figs. 26, 27).

Burial offerings at El-Zuma comprise various items characteristic of the period. As usual, pottery constitutes the bulk of the grave goods, which also include adornments, as well as iron arrowheads and one rare example 
of leatherwork (for details of the pottery recovered from the El-Zuma burials see Volume II). However, a number of vessels discovered during the third season deserve some brief comments. There is no doubt that T.11 must have been well-furnished with grave offerings that testify to the social standing of the burial's occupant. The loss of chamber 1 (the main burial chamber) is a great pity, for one would always expect it to contain some type of personal item that could provide much more information about the buried individual, or the period in general, especially given that all the main burial chambers hitherto excavated were found robbed. However, chamber 2 contained a wide range of pottery and food. Although the pottery assemblage in general falls within the types produced in the Dongola Reach during the Early Makurian period, four types of vessels are especially noteworthy. One bowl form was observed in this type of burial for the first time. The bowls designated Z11/4, Z11/7, Z11/8, Z11/9, Z11/13, Z11/21 (see Volume II, page 196 and Fig. 7.92) are distinguished by a rounded base and flared sides with squared rims. In spite of the fact that they are classified in the same category as the well-known, small, undecorated red-ware bowls, they are finely made and slightly larger in size. Most probably these vessels were locally produced; however, they might have been made by a more skilled potter or potters. Two red-ware cups from chamber 1 (Z11/6 and Z11/10: see Volume II, page 177 and Fig. 7.90) represent a form which had not previously been noted among locally produced vessels, except for one example from Tanqasi T. 87 (Klimaszewska-Drabot 2010a, 220, Fig. 3). They are characterized by a rounded profile, a simple applied rounded rim and slightly flattened base, and a slipped and burnished but undecorated external surface. Apparently, this form is an imitation of the short X-Group cups, usually decorated with two or three incised grooves on the lower part, just above the base, like the ones found at the Roм 32/1 site (see Phillips 1987, 35-41; Grzymski 1991, 18, 23, Figs. 5, 6; Williams 1991). A unique form of bowl was found amongst the pottery in chamber 2 of T.11. Cup Z11/3o (see Volume II, page 207 and Fig. 7.101) measures about $8.4 \mathrm{~cm}$ in height and $12 \mathrm{~cm}$ in rim diameter. It has a rounded base and strongly flared rim. The external surface is red-slipped and burnished, while the interior is covered with white paint. To the best of our knowledge, such a practice has never previously been noted, either in this region or elsewhere in Nubia. A particularly significant and interesting find was a distinctive type of large, deep, wheel-made bowl. Five vessels of this type were found in T.11, chamber 2: Z11/17, Z11/22, Z11/29, Z11/34, and Z11/35 (see Volume II, pages 181182 and Fig. 7.92). On average these bowls measure about $7.7 \mathrm{~cm}$ in height and about $15 \mathrm{~cm}$ in rim diameter. They testify to cultural continuity, as this type of bowl originated in the Meroitic period and remained in production with continuous modifications until the Second Phase of the Early Makurian period (late post-Meroitic), varieties of it having been recorded throughout Lower and Upper Nubia. The simplest form, found at El-Kadada in a Meroitic burial, has a heavy hemispherical body of about $6.5 \mathrm{~cm}$ in height and $15 \mathrm{~cm}$ in rim diameter. Another variant is slightly larger, reaching up to $18 \mathrm{~cm}$ in rim diameter and about $7 \mathrm{~cm}$ in height, with sides out-flared, and a flattened base (Lenoble 1987, Pl. IV c, 20). A more developed version of the same type was found in the Meroitic part of the cemetery at Gabati, some $75 \mathrm{~km}$ north of El-Kadada, with standard dimensions of $12 \mathrm{~cm}$ in rim diameter and $9 \mathrm{~cm}$ in height (Edwards 1998, 158, Figs. 6.12 bottom, 6.13). A parallel, but larger variant of this vessel, measuring about $9.1 \mathrm{~cm}$ in height and $14.6 \mathrm{~cm}$ in rim diameter, was discovered in the West Cemetery at Meroe (Dunham 1963, v:189, Figs. 135; 342, F). In the Dongola Reach, bowls of this type were found in a late Meroitic burial at Hagar Sail, and at the Early Makurian (post-Meroitic) cemetery of El-Kassinger Bahry in the Fourth Cataract region, as well as in T.1o at El-Zuma and T.87 at Tanqasi (Klimaszewska-Drabot 2010a, 221, Fig. 3). The first two (Z11/17 and Z11/22) resemble an El-Kadada bowl (Lenoble 1987, Pl. IV c). Despite the larger size of the latter, and to some extent their varying quality of manufacture, the general shape is similar. The vessel walls are either rounded or out-turned to form small ledges or bevelled rims. The bases are often of irregular, rounded, flattened, conical shape, and in some versions they have a low ring base. Surface treatment tends to be wet-smoothed and burnished, or coated with red slip inside and out, executed with different degrees of care. A very large handmade vessel in a dark brown ware, so far only known from T.11 at El-Zuma, is a large bowl of $25 \mathrm{~cm}$ in height and $40 \mathrm{~cm}$ in rim diameter, which is characterized by a rounded profile, thick walls and flattened base. A number of small holes perforated on both sides of a long crack, extending from top to bottom, are signs of repair, leaving no doubt that the bowl was used for a considerable span of time before being deposited in the burial. The large bowl Z11/16 (see Volume II, page 212 and Fig. 7.103) was discovered in chamber 2, which contained only grave offerings. Some animal bones were found in situ inside it. This can be taken as a direct indication of the function of the vessel. It could, like the later large Funj black ware dishes or even the wooden gadah of the 19th century, have been used for serving food. Attention should also be drawn to the small red bowl Z13/28 (see Volume II, page 206 and Fig. 7.100) found in chamber 3 of T.13. Although in size and texture this bowl bears a resem- 
blance to the distinctive red bowls of the Dongola Reach, its execution was unique: it has a slightly flattened base, turned-out profile, a tapered in, applied rim, and three wide grooves incised about $10 \mathrm{~mm}$ below the rim. To the best of our knowledge, this wonderful vessel has no parallel elsewhere in Nubia. Some fragments from two different vessels require a brief comment. Both varieties of sherds represent well-known forms, frequently found at Christian sites; the first is a handmade cooking pot distinguished by a recurved rim and rounded body covered with a mat-impressed pattern. The second is a wheel-made qadus. These sherds were found in the shaft fill of T.11. Their presence in the plundered shaft has raised doubts about their original location: were they thrown out from one of the two chambers by the robbers, or thrown down the shaft by someone else? Although the qadus was common in Nubia from the Meroitic period onwards, at this cemetery only the one under discussion has so far been found; however, its presence in the shaft is not that surprising, as it may have been part of the original grave goods. As for the cooking pot, different forms of cooking vessels were found in T.11, as well as in other burials at this cemetery. However, only one incomplete vessel very similar to the one discussed here, with a rounded body and recurved rim, was found in the tunnel of El-Zuma T.5, excavated in 2007. Its original location is also uncertain, as it was found in the sediment that partially filled the tunnel; therefore, it is hard to know whether it got there as part of the later fill, or whether it was among the original grave offerings. If this vessel had originally been deposited in the burial, it could mean that the first appearance of the characteristic recurved cooking pot is earlier than the Christian period to which it is usually attributed.

A rare find from burials of the period is the leather case discovered in T.11, chamber 4 (see Volume III, Chapters 8 and 18). This object lay near three small red bowls and was found in a fragile, fragmentary state. A number of beads were scattered between and around the leather fragments. Prior to this, only three leather cases of this type had been found in the region. The first came from T.1 at the Southern Cemetery of EL-Ghaddar, followed by another from T.1, chamber 2 at Hammur-Abbassiya, whilst the third was found in the main burial chamber at El-Kassinger Bahry cemetery 45/T.1 (Mahmoud El-Tayeb 1994, 66; Kołosowska and Mahmoud El-Tayeb 2007, 15-16, Fig. 13). In the case of El-Ghaddar, the object was thrown out of the plundered burial chamber. The second example was recovered from the ransacked main burial chamber, whereas at El-Kassinger Bahry, the leather case was found at the feet of the deceased in an unlooted chamber. In each of the four instances there was no evidence that these cases contained anything, which begs the question: what was the real function of such objects and why were they deposited in graves? Today such leather bags are still in use, especially by nomadic communities. Depending on their design, they can serve as a water-skin (Arabic: girba), a sack for carrying things (jurab), or a sack for shaking milk (sea'in). The exact function of the excavated leather objects remains obscure. However, a regular row of holes pierced along the edges of the hide fragments found at El-Zuma is an indication that the case was made either from one folded piece of leather or two pieces stitched together and additionally decorated with some beads. If this theory is correct, then the leather object must have been a jurab. This still leaves unanswered the question of why it was deposited so far away from where the body was buried.

Food was also present among the grave goods in almost all the excavated burials. Butchered fragments of bones were found scattered amongst the pottery vessels. In chamber 1 of T.11, a pile of large animal bones (probably cattle) was recorded near a large cooking pot at the west end of the east-west aligned burial chamber. Cattle bones were mainly found in burials designated as types I and II, while meat of small species (sheep or goat) were predominant in type II burials. Cattle meat appears to have been included as an offering with elite individuals, testifying to their high status.

Adornment is mainly confined to beads made of different materials, and, as is usual in this period, beads are a constant feature of the burial inventory. Approximately 101 various beads of blue faience, quartz, and agate, in addition to a small scarab of blue faience, were found in T.27 in the area around the disturbed skull; they were probably part of a necklace. One badly eroded iron ring and 88 small beads were found in T.17.

Weapons frequently accompanied the deceased. Two types of iron arrowheads were represented. The most common type is the single-barbed arrowhead; the second type, which is less common, is barbless. Other unidentified iron fragments were found in the burials, and one stone archer's ring was found in T.27 (see Volume III, Chapter 13).

To summarize, each season of excavations at the ElZuma cemetery brought to light some new elements of burial traditions in tumuli of types II and III. In terms of tomb construction, the first recorded instance of a subtype of type II tumuli was represented by the superstructure and substructure of T.11, an aspect that needs further investigation. Another structural modification is the trapezoidal shaft noted in a number of burials of type III. To date, four burials with trapezoidal shafts have been discovered at this site, which, in conjunction with the pres- 
ence of such shafts at other burial grounds in the same region, clearly shows elements of continuity between Meroitic and Early Makurian burial traditions.

The appearance of some vessel forms that had not been noted during the first seasons indicates the wide-ranging repertoire and expertise of the local pottery workshops. A more exciting discovery is that of large reused red bricks of Meroitic origin. Most probably, these were brought from a Meroitic temple or other official building located somewhere in the vicinity.

Initially, it was thought that the tumuli at El-Zuma could be classified using a very simple typology, but it has transpired that a rather more complicated one is needed, despite the fact that the burials are of the same chronological horizon. Undoubtedly, further detailed analysis of the cemetery and the excavated material is required for a better understanding of this important site representing a poorly studied period.

In conclusion, the discoveries made at El-Zuma clearly demonstrate the cultural continuity and evolution of Meroitic traditions, which is evident, for example, in the funerary customs, grave offerings, and pottery. Consequently, it would be more accurate to date the El-Zuma cemetery to the Terminal Meroitic period rather than the one-hundred-year-later post-Meroitic period. 